UCRL-JC-122874

CONF $-960477-5$

\title{
Complex Electrical Resistance Tomography of a Subsurface PCE Plume
}

\author{
A. Ramirez \\ W. Daily \\ D. LaBrecque
}

This paper was prepared for submittal to the Symposium on the Application of Geophysics to

Engineering and Environmental Problems

Keystone, $\mathrm{CO}$

April 28-May 1, 1996

January 1996

This is a preprint of a paper intended for publication in a journal or proceedings. Since changes may be made before publication, this preprint is made available with the understanding that it will not be cited or reproduced without the permission of the author.

DISTRIBUTION OF THIS DOCUMENT IS UNLIMTTED, 


\section{DISCLAMMER}

This document was prepared as an account of work sponsored by an agency of the United States Government. Neither the United States Government nor the University of California nor any of their employees, makes any warranty, express or implied, or assumes any legal liability or responsibility for the accuracy, completeness, or usefulness of any information, apparatus, product, or process disclosed, or represents that its use would not infringe privately owned rights. Reference herein to any specific commercial product, process, or service by trade name, trademark, manufacturer, or otherwise, does not necessarily constitute or imply its endorsement, recommendation, or favoring by the United States Government or the University of California. The views and opinions of authors expressed herein do not necessarily state or reflect those of the United States Government or the University of California, and shall not be used for advertising or product endorsement purposes. 


\title{
Complex Electrical Resistance Tomography of a Subsurface PCE Plume
}

\author{
Abelardo Ramirez, William Daily \\ Lawrence Livermore National Laboratory \\ Livermore, CA 94550 \\ and \\ Douglas LaBrecque \\ University of Arizona \\ Tucson, Arizona 85721
}

\begin{abstract}
A controlled experiment was conducted to evaluate the performance of complex electrical resistivity tomography (CERT) for detecting and delineating free product dense non aqueous phase liquid (DNAPL) in the subsurface. One hundred ninety liters of PCE were released at a rate of 2 liters per hour from a point $0.5 \mathrm{~m}$ below ground surface. The spill was conducted within a double walled tank where saturated layers of sand, bentonite and a sand/bentonite mixture were installed. Complex electrical resistance measurements were performed from 4 vertical electrode arrays, each with 10 electrodes spaced between $3 \mathrm{~m}$ and $0.5 \mathrm{~m}$ depth. Data were taken before the release, several times during, and then after the PCE was released. Magnitude and phase were measured at 1 and $64 \mathrm{~Hz}$. Data from before the release were compared with those during the release for the purpose of imaging the changes in conductivity resulting from the plume. Conductivity difference tomographs showed a decrease in electrical conductivity as the DNAPL penetrated the soil. A pancake-shaped anomaly developed on the top of a bentonite layer at $2 \mathrm{~m}$ depth. The anomaly grew in magnitude and extent during the release and borehole television surveys data confirmed the anomaly to be free-product PCE whose downward migration was stopped by the low permeability clay. The tomographs clearly delineated the plume as a resistive anomaly. Images showing phase changes caused by the spill are also presented. The phase changes at $64 \mathrm{~Hz}$ suggest that the DNAPL spill increased the induced polarization (IP) effect of the clay layers.
\end{abstract}

\section{INTRODUCTION}

Large volumes of hydrocarbons have contaminated numerous aquifers. The contaminated soil contain both dissolved phase hydrocarbon as well as free product. 
Current contaminant detection methods require the extensive use of core drilling and chemical analysis of soil samples to map the extent of the subsurface plumes. Relatively recent work by Olhoeft (1992), Borner et al (1993) and others suggest that complex resistance measurements may provide a method to detect organic contamination in soils.

The proposed CERT may minimize the need for drilling and for chemical analyses of large numbers of soil samples if it can be shown to be capable of defining regions contaminated with free product DNAPL. We describe here the results of a controlled field experiment where complex electrical resistivity tomography (CERT) was used to detect and locate complex resistivity changes during a PCE spill conducted in a layered soil medium.

This work was performed at the Oregon Graduate Institute of Science and Technology (OGI) in Beaverton, Oregon because the facilities there include a unique double-wall tank filled with soil into which a contaminant can be legally released at a scale sufficiently large to see physical phenomena at a realistic scale. The $10 \mathrm{~m}$ square and $5 \mathrm{~m}$ deep tank is instrumented for geophysical and hydrological studies. Layers of sand, bentonite and sand/bentonite mixtures were constructed within the tank to simulate a layered soil system (refer to figure 1 for details). Soil pore water consisted of a dilute $\mathrm{NaCl}$ solution with a resistivity of $40 \mathrm{ohm}-\mathrm{m}$. The DNAPL was dyed so that its location could be determined using borehole television surveys. A more complete description of the OGI facility is given by Johnson et al., 1992.

Three boreholes in the tank were each instrumented with 10 electrodes. The reconstruction model assumes a resistivity distribution constant in the direction perpendicular to the plane defined by the electrodes although electrical potential is modeled three dimensionally to permit point electrodes. The soil-air interface is a boundary of zero normal current flow. After reconstruction, the tomographs are spatially smoothed to give the appearance of a continuous resistivity distribution. The mesh elements were approximately square and there were two elements between each electrode along the boreholes. The algorithm used for these inversions is described by LaBrecque et al. (1995).

Data were collected using a frequency domain, multichannel resistivity meter. The surveys were performed at five frequencies between 1 and $1024 \mathrm{~Hz}$. Each data set 
consisted of 660 data points, and half of the data set consisted of the reciprocals for the other half. Data collection time for each data set at a single frequency was about 15 minutes.

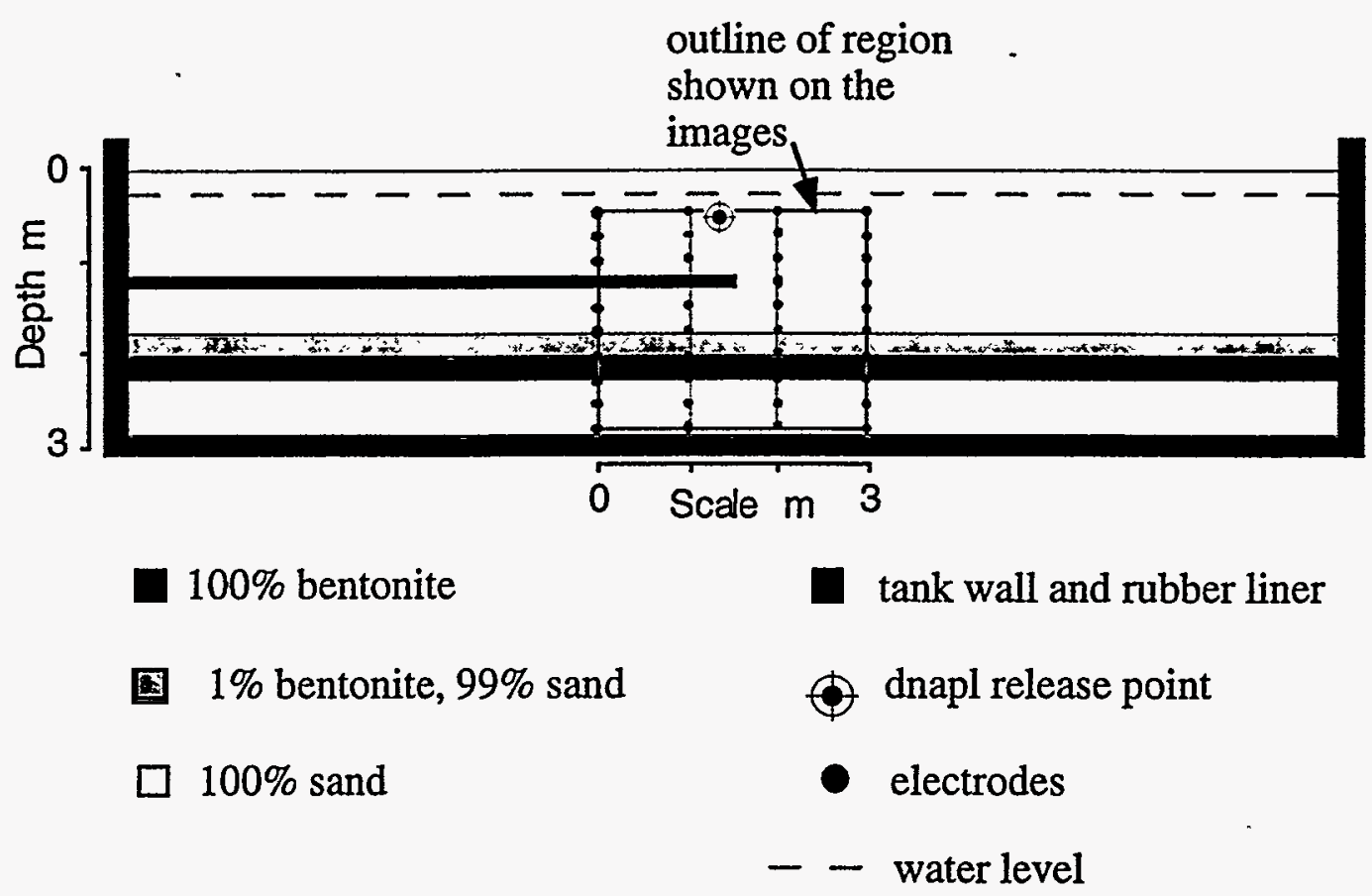

Figure 1. The DNAPL was released within the confines of a double wall tank and CERT measurements were made using electrodes installed within the soil. Layers of sand, bentonite and sand/bentonite mixtures were constructed to simulate a layered medium.

\section{ELECTRICAL CONDUCTIVITY CHANGES DURING THE SPILL}

A total of 190 liters of PCE were released over a 4 day period from August 16 through 20,1995 . This amounted to a rate of about $2 \mathrm{l} / \mathrm{hr}$ released from a single point $0.5 \mathrm{~m}$ below the surface and approximately located above the center of the electrode arrays. The water level was stable at a depth of $25 \mathrm{~cm}$ for approximately 6 weeks before the release started.

CERT data were taken before, several times during and again after the release. The data taken before the release were used as baseline. Reciprocal measurements were made 
each time data were collected and used to provide estimates of measurement noise needed for inversion.
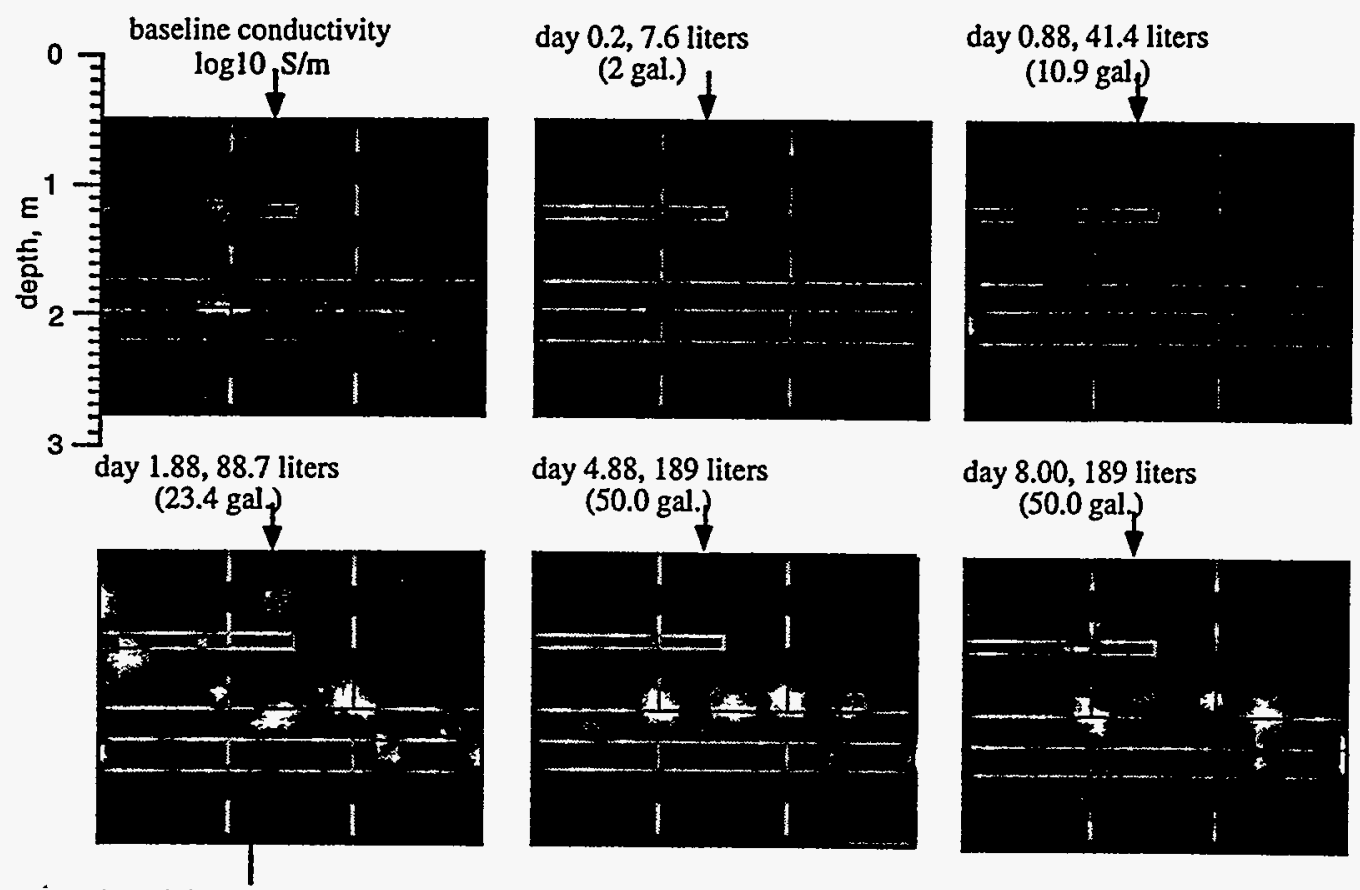
day $20.0,189$ liters
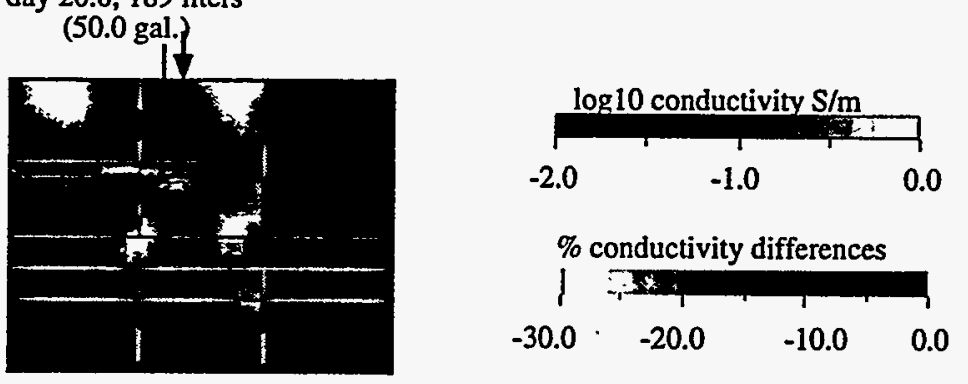

Figure 2. The 'baseline' tomograph taken on August 16 (top left corner) and percent conductivity difference images recorded during the PCE release. The tip of the arrow shows the location of the release point. The outlines of the bentonite layers and the sand/bentonite mixture are shown for reference.

Fig. 2 shows the day 0.0 'baseline' image (top left hand corner) with the conductivity structure prior to the release. The outlines of the bentonite and sand/bentonite layers are shown by the dotted lines. As expected, the highest conductivities are seen along the clay layers while the sand sections show the lowest. The top clay layer thickness is somewhat 
exaggerated and its width is underrepresented. The bottom clay layers' thicknesses are more accurately represented. The image thicknesses for both layers is roughly equal. The actual thickness of the lower clay is about $20 \mathrm{~cm}$, the overlying sand/bentonite layer is 25 $\mathrm{cm}$ and the upper clay is only about $7 \mathrm{~cm}$.

The remaining images in Fig. 2 are percent conductivity difference images showing the changes measured during and after the spill sequence ended. Negative differences mean that the conductivity has decreased relative to the 'baseline' case. One hertz data was used to calculate these tomographs. As early as day 0.2 (day 0.0 marks the start of the release) we notice a subtle conductivity decrease formed directly below the release point. This small change is of the same order as other changes seen away from the release point where no change is expected; these changes are thought to be caused by measurement error. On days 0.88 and 1.88 , the conductivity decrease below the release point grows in magnitude and appears to bend around the upper bentonite layer and reach the top of the sand/bentonite unit.

The spill ended on day 4.0; when a total of 190 liters had been released. On day 4.88 the finger-like anomaly below the spill has dissipated; also note that the conductivity decrease above the sand/bentonite layer has grown in magnitude and lateral extent. The resistive anomaly above the $1 \%$ sand/clay layer and $100 \%$ clay layer breaks up into individual pockets of reduced conductivity on day 20 . Other large conductivity decreases can be observed near the top center and top right sections of the image for day 20 . These decreases are probably unrelated to the DNAPL spill since they develop 16 days after the spill ended. Heavy rainfall occurred at the site during this period; we speculate that these conductivity decreases are probably caused by rain water infiltrating through holes on the tarp which covered the ground surface. Rain water probably drained through these holes, reducing the ionic content of the pore water and thereby decreasing the local conductivity.

We interpret these conductivity decreases to mean that the electrically insulating, free product PCE has displaced some pore water, thereby decreasing the bulk conductivity. In saturated soil, the PCE sinks until it hits an impermeable layer such as clay. The PCE then spreads laterally on top of the impermeable barrier and forms a pool until it can find a pathway around or through the barrier. We do not understand the apparent breakup of the PCE "pool" after the spill ended; the anomalies suggest that, initially, the PCE forms 
a continuous layer when it reaches the clay and then breaks up into individual pockets as the DNAPL continues to move laterally. The location of the free-product PCE pool was independently confirmed using borehole television surveys which located the dyed PCE; these surveys were made through glass casing by R. Johnson and W. Bagby (OGI).

Conductivity increases were also observed in the conductivity difference images. During the course of the experiment, we discovered that, while free-product PCE has a very high resistivity, water that comes in contact with the free product will suffer conductivity . increases. This was determined in a simple experiment. We made conductivity measurements of water in a beaker before and after PCE was added. A piece of PVC pipe was included in the beaker because PVC pipes were present in the tank. This experiment showed that the water conductivity increased by about $55 \%$. We do not know the cause of the conductivity increase. Perhaps a chemical reaction between the PVC and PCE causes reaction products that increase the water conductivity.

\section{PHASE ANGLE CHANGES DURING THE SPLLL}

The phase angle $\phi(\omega)$ is defined as the angle between the in phase and quadrature conductivities (Vinegar and Waxman , 1984)

$$
\phi(\omega)=\tan ^{-1} \frac{\sigma_{i}(\omega)}{\sigma_{q}(\omega)}
$$

where $\sigma_{i}(\omega)$ is the in phase conductivity and $\sigma_{q}(\omega)$ is the quadrature conductivity. To calculate $\phi(\omega)$, we inverted the real and imaginary conductivities and then substituted them into equation 1. Phase angle differences were then calculated by subtracting the "baseline' phase angle from phase angles measured during the spill. 


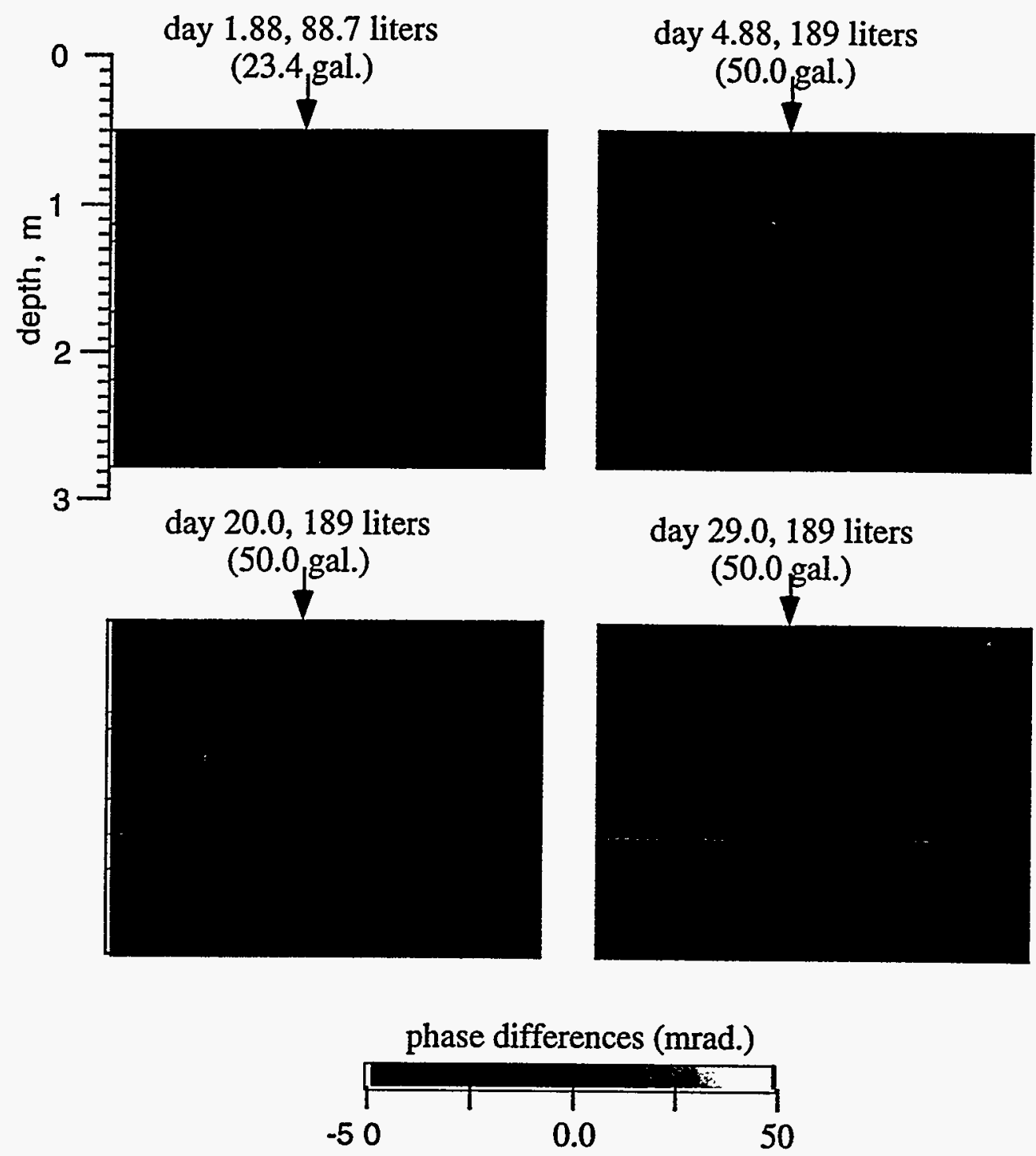

Figure 3. Changes in phase during the experiment for the $64 \mathrm{~Hz}$ data. The tip of the arrow shows the location of the release point. The outlines of the bentonite layers and the sand/bentonite mixture are shown for reference.

Figure 3 shows the phase difference images for the $64 \mathrm{~Hz}$ frequency data. These images were created by subtracting the baseline phase tomograph from subsequent phase tomographs. Negative differences indicate that the phase became more negative relative to the baseline and suggest that the soil is becoming increasingly polarizable. The figure shows the differences calculated after 89 liters had been spilled (midway through the spill 
sequence), shortly after the spilled ended (4.88), about two weeks later (day 20) and after about 3.5 weeks. Midway through the spill, both positive and negative differences in phase occur. As time progresses, the negative differences become larger, particularly along the contact between the $1 \%$ sand/bentonite and $100 \%$ bentonite units. There is also a significant phase change above the upper bentonite layer. This is consistent with our conceptual model which assumes that PCE would 'pool' above the clay layers. The negative differences appear as pockets that grow wider and thicker with time. This behavior suggests that, if the observed changes are caused by the PCE, the PCE is penetrating the clay faster in some places than others.

The largest phase increases are concentrated along the contact between the $1 \%$ bentonite/sand layer and the lower bentonite layer and along the upper clay layer. These results suggest the magnitude of the IP effect increased near the clay layers during the course of the spill. This observation is consistent with complex resistivity data presented in Olhoeft (1992). His data shows that, in the 10 to $100 \mathrm{~Hz}$ range, the IP effect is enhanced by the toluene contamination. However, the data from Olhoeft show a smaller frequency shift than that shown in the phase difference images; we do not know the reason for the relatively high phase shift implied by the images. Future work will address the phase changes related to the other frequencies measured.

A comparison of Figures 2 and 3 shows both similarities and differences. Both figures show large changes near both bentonite layers. The main difference between the figures is that the conductivity changes in Figure 2 are mostly observed in the $1 \%$ bentonite layer and just above it; the phase changes in Figure 3 appear centered on the boundary between the $1 \%$ and $100 \%$ bentonite layers. A possible explanation for this is presented by King and Olhoeft (1989). Their work explored the effects of toluene on clay minerals (montmorillonite). They concluded that the magnitude of the complex resistivity is related to volume effects (charge transport) whereas the phase is related to surface concentration and processes. Assuming that the PCE contamination interacts with clays in a fashion similar to toluene interaction, we can use their conclusions as guidance. We might expect that the largest changes in magnitude would occur where the largest volume of DNAPL penetrated the pore space. In the OGI test, we would expect the largest volume of DNAPL to be present in the sand units. The largest changes in phase may be expected where there contact surface area between the clay and the DNAPL is the largest, i.e., along the contact between the $1 \%$ bentonite/ sand layer and the $100 \%$ bentonite layer, 
and within the $100 \%$ bentonite layer. Thus, we suggest that Figures 2 and 3 show results consistent with King and Olhoeft 's work.

\section{SUMMARY}

The work described here has been performed to determine the feasibility of using CERT to detect and locate subsurface DNAPL. A PCE spill was conducted within the confines of a double walled steel tank having layers of saturated sand, bentonite and sand/ $1 \%$ bentonite. Measurements of resistance magnitude and phase were made at frequencies of $1,64,256,512$, and $1024 \mathrm{~Hz}$ prior to the spill. The measurements were then repeated at various times during after the spill sequence. Tomographs of electrical conductivity were calculated. Conductivity difference tomographs were generated by subtracting the pre spill 'baseline' tomograph from subsequent tomographs. The observed changes are in the 20-30\% range. The difference tomographs suggest that the free product PCE moved through the upper sand layer, flowed around the upper clay layer and came to rest above the lower clay layer. At the spill's end, the tomographs show a spatially continuous anomaly suggestive of a 'pool' of free product formed above the lower clay layer within the $1 \%$ bentonite/sand layer. This spatially continuous anomaly then separated into discrete pockets in the weeks following the spill. Phase angle changes were also estimated. Differences in phase suggest that the clay became more polarizable as the PCE reached the bentonite rich layers.

The approach followed in this paper relies on observing differences in time to locate the DNAPL. This approach is only suited for cases where one is able to make measurements while the DNAPL spill changes the soil's electrical properties; clearly this is not possible in most cases. Our work is continuing with the goal of identifying DNAPL contaminated regions using only the frequency dependent changes in complex resistivity.

\section{REFERENCES}

Borner, F., M. Gruhne, and J. Schon, 1993, Contamination Indications Derived from Electrical Properties in the Low Frequency Range, Geophysical Prospecting, vol. 41, pp. 83-98.

King, T., and G. Olhoeft, 1989, Mapping Organic Contamination by Detection of Clay Organic Processes, Proc. Petroleum Hydrocarbons and Organic Chemistry in Ground Water: Prevention, Detection and Restoration Conf., Nov. 15-17, Houston, pp. 627-640. 
LaBrecque, D. J., W. Daily, E. Owen and A. Ramirez, 1995, Noise and OCCAM's Inversion of Resistivity Tomography Data, Geophysics, in press,.

Johnson, R. L., W. Bagby, M. Perrott, and C. Chen, 1992, Experimental Examination of Integrated Soil Vapor Extraction Techniques, in Proceedings of the 1992 Petroleum Hydrocarbons and Organic Chemicals in Ground Water: Prevention, Detection and Restoration, (November 4-6, Houston, TX).

Olhoeft, G., 1992, Geophysical Detection of Hydrocarbon and Organic Chemical Contamination, Proc. Symposium on the Application of Geophysics to Engineering and Environmental Problems, R. S. Bell ed., April 26-29, p. 587-595.

Shuey, R. T., and M. Johnson, 1973, On the phenomenolology of electrical relaxation in rocks, Geophysics, vol. 38, no. 1, p. 37-48.

Vinegar, H. J., and M. H. Waxman, 1984, Induced polarization of Shaly Sands, Geophysics, vol. 49, no. 8, pp. 1267-1287.

\section{ACKNOWLEDGMENTS}

This work benefited from the contributions and talents of many colleagues. Prof. $R$. Johnson, M. Perrot and especially W. Bagby helped to plan the experiment, constructed the tank layers, conducted the spill process and collected corroborating data such as borehole TV logs and neutron logs. R. Newmark assisted in data collection and J. Beatty developed the data acquisition software. This work was performed under the Environmental Technologies Program at LLNL. It was funded by the Characterization, Monitoring and Sensors Tech. Program, Office of Technology Development, U.S. Department of Energy (DOE). This study is based on work performed under the auspices of the U.S. Department of Energy by the Lawrence Livermore National Laboratory under contract W-7405-ENG-48. 


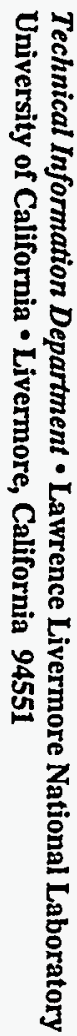

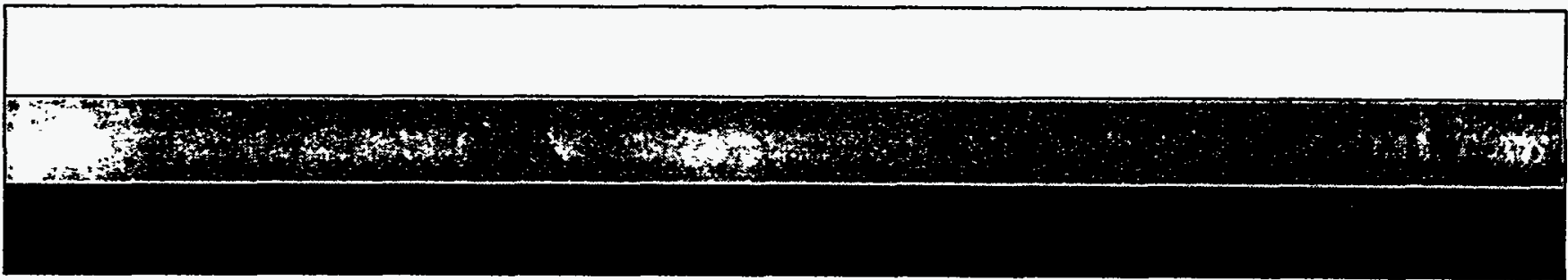

